\title{
Direct Seeding of Soybean Using a Modified Conventional Seeder
}

\author{
Davut Karayel \\ Akdeniz University \\ Turkey
}

\section{Introduction}

A seeder should place seed in an environment for reliable germination. The main objective of sowing is to put seeds at a desired depth and spacing within the row. Uniform seed distribution within the soil result in better germination and emergence and increase yield by minimizing competition between plants for available light, water, and nutrients. A number of factors affect seed distribution in soil. Seed metering system, seed delivery tube, furrow opener design, physical attributes of seed and soil conditions all play a part in determining seed distribution.

Conservation tillage is defined to be any tillage or sowing system which leaves at least $30 \%$ of the field covered with crop residue after sowing has been completed. In such soils, erosion is reduced by at least $50 \%$ as compared to bare, fallow soils. In the last three decades, no-till sowing practices that promote soil and water conservation have slowly become an accepted alternative to conventional tillage systems.

Improvements in the design of minimum and no-till seeders, lower cost and more effective herbicides, a better understanding of the role of tillage in crop production systems, and an increased emphasis on residue management have been key factors in the successful shift to no-till sowing (Baker et al., 2002).

The continuous development of conservation tillage technologies has led to studies on the performance of seeders. No-till sowing requires a seeder that will effectively penetrate untilled soil and place the seed at the optimum depth for rapid plant emergence.

No-till seeders and drills must be able to cut and handle residue, penetrate the soil to the proper sowing depth, and establish good seed-to-soil contact. Many different soil conditions can be present at the time of sowing. Moist soils covered with residue, which may also be wet, can dominate during late fall and early spring and occasionally in the summer. Although this provides for an ideal seed germination environment, such conditions can make it difficult to cut through residue. In contrast, hard and dry conditions may also prevail. This is especially common when no-tilling soybean into wheat stubble during the hot, dry months of June and July. Although cutting residue is easier during dry conditions, it is more difficult to penetrate the hard, dry soils. Proper timing, equipment selection and adjustments, and management can overcome these difficult issues.

Two of the keys for success with no-till equipment are proper handling of the previous crop residue and weed control. If these issues are not considered, then the ability of the seeder or drill to perform its functions is greatly limited. The residue has to be uniformly spread 
behind the combine if the opening devices are going to cut through the material and plant at a uniform depth. It is very difficult for the seeder to cut the residue if the combine has left a narrow swath of thick residue and chaff (Grisso et al., 2009).

Probably the primary difference between conventional seeder systems and those designed for conservation tillage systems is weight. Since the openers and soil engaging devices must penetrate much firmer soils and cut the residue, the conservation seeder systems are built heavier and have the ability to carry much more weight than conventional systems. For adequate coulter penetration, weight may have to be added to the carrier. Some seeder use a weight transfer linkage to transfer some of the tractor weight to the coulters to ensure penetration. Because coulters are usually mounted several feet in front of the seed opening/placement device (in the case of coulter caddies even further), many use widefluted coulters, a pivoting hitch or a steering mechanism to keep the seed openers tracking in the coulter slots.

Wide-fluted coulters (5-8 $\mathrm{cm}$ wide) perform the most tillage and open a wide slot in the residue. They allow faster soil warm-up (which may be a disadvantage in some doublecropping situations) and prepare an area for good soil-to-seed contact. However, because of the close spacing, fluted coulters require more weight for penetration, disturb more soil surface, and bury more residue. In wet soil conditions, fluted coulters may loosen too much soil, which could prohibit good seed-to-soil contact. The loose, wet soil may stick to the seed openers and press wheels resulting in non-uniform depth control and clogging.

Narrow-fluted coulters or narrow bubble coulters, ripple coulters and turbo-rippled coulters do not require as much weight for penetration and do not throw as much soil out of the seed furrow as the wide-fluted coulters.

Most no-till seeder is equipped with independent sowing units that should allow at least $15 \mathrm{~cm}$ of vertical movement. This will allow smooth transit over non-uniform surface and adjust for root stubs and other obstacles. These units are sometimes staggered which helps with the unit function (more side-to-side space) as well as more space for the residue to flow through the system. These units should be equipped with heavy down-pressure springs and sufficient weight to ensure penetration of both the coulters and seed furrow openers into untilled soil. Usually these springs are adjustable and multiple springs can be added until sufficient pressure is achieved.

Some no-till seeders are not equipped with coulters. These seeders use the seed furrow openers to cut and place the seed. Several seeder systems have a staggered double disk seed furrow opener without a coulter. The leading disk cuts the residue and the second aids in opening the seed furrow. Some manufacturers use a single, large disk set at a slight angle. These units require less weight.

Sufficient weight must remain on the press wheels to ensure firming of the seed into the soil. Wet soil is easily compacted and care must be taken not to over pack the soil, making it difficult for seedling roots to penetrate the soil. In dry soil conditions, extra closing force may be needed. The key is to evaluate seed-to-soil contact, not the top of the seed-vee. As long as the contact is there, something as simple as a harrow that acts to close the top of the vee and pull light residue cover back over the vee may be all that is needed. This is a common practice on drills that use a narrow press wheel (Grisso et al., 2009).

Depth control of most no-till seeder systems comes in three methods:

1. front wheel in front of the seed furrow opener,

2. side gauge wheel adjacent to the seed furrow device, and

3. presswheel behind the seed furrow opener. 
In all three cases, keep adequate pressure on the front, gauge or press wheel to force the openers into the soil to the proper depth. A harrow behind a seeder ensures seed coverage and redistributes residue for effective conservation measures. Regardless of the depth control, wide-flat press wheels are unacceptable for no-till since they will ride on the firm soil adjacent to the seed furrow and will not firm the seed into soil. A wide press wheel equipped with a rib that runs on the sides of the seed furrow or a rib that runs directly over the furrow to press the seed is adequate for good seed-to-soil contact. Karayel and Ozmerzi (2009) evaluated three depth-control components in two different field conditions (Fig. 1). Runner and double disc openers were used with each depth-control. The vertical and horizontal distribution of seeds in the soil and percentage of emerged seedlings were determined to evaluate performance of depth-control components. The horizontal distribution of seeds was described by using the mean, standard deviation, and coefficient of variation of seed spacings. The vertical distribution of seeds was described by using the distribution area of seeds in addition to the mean, standard deviation, and coefficient of variation of sowing depths. Mean seed spacing was not affected by depth-control component but mean sowing depth was affected. The minimum coefficient of variation of sowing depth and distribution areas of seeds were obtained with the side gauge wheel. The best choice for depth-control is side gauge wheel according to uniformity of vertical distribution of seeds and percent emergence. The poorest choice for depth-control is the rear presswheel which malfunctioned by sinking into loosened soil and produced deeper and the most variable sowing depths.

Morrison and Gerik (1985a \& b) evaluated four depth-control components with grain sorghum and maize crops for no-tillage seeders. Depth-control components affected mean depth of sowing and depth variations. They also evaluated seeder depth-control on the basis of the predicted effects on simulated emergence for four crops. A linked front and rear depth-control wheel performed similar to rear and front depth-control wheels. Side gauge wheel were the least sensitive to type of crop residue, but required higher down pressure levels to minimize sowing depth variations.

Chen et al. (2004) investigated effects of presswheel, gauge wheel and fertilizer banding attachment on the selected seeder and crop performance. When presswheels or/and gauge wheel were not used, delayed emergence, reduced plant population and yield were observed in the normal and dry soil condition, while better crop emergence and comparable yield were obtained in the very wet sowing condition.

Soybeans are usually planted with either an agronomic row crop seeder or a grain drill. A grain drill is typically used for very narrow row configurations. Grain drills are less expensive per row than row-crop seeders but do not deliver the same metering uniformity. Soybean farmers have expressed a need for an alternative seeder combining the uniformity of a row-crop seeder with the lower cost of a grain drill.

Ess et al. (2004) conducted a research on conventional fluted-meter devices to evaluate them for variable rate soybean sowing. Fluted-meters have a cup on a rotating shaft and then an opening gate. The device performed very poorly for this test and showed that changing shaft speed or forward speed or gate opening greatly hindered the accuracy of population and spacing of the seed. As the seeds increased in size, the variability was even greater.

The drill meter devices were usually not considered for singulation accuracy because the small grains can usually compensate for the inconsistency. This may not be the case for soybeans. Some accuracy and spacing uniformity can be gained with very specific travel 
speeds and fixed population but this degrades quickly if travel speed is not consistent. Another problem that contributed to the lack of spacing uniformity was the distance from the seed meter device to the seed furrow. The seed bounce and travel in the seed delivery tube greatly influenced the spacing uniformity.

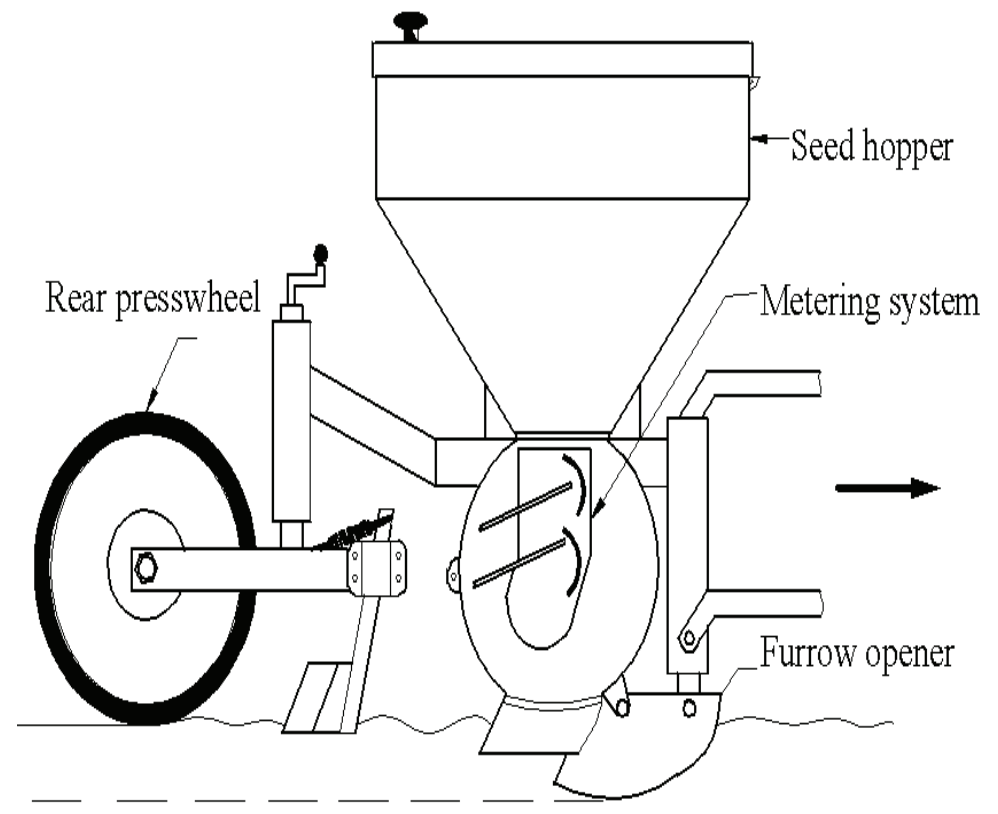

(a)

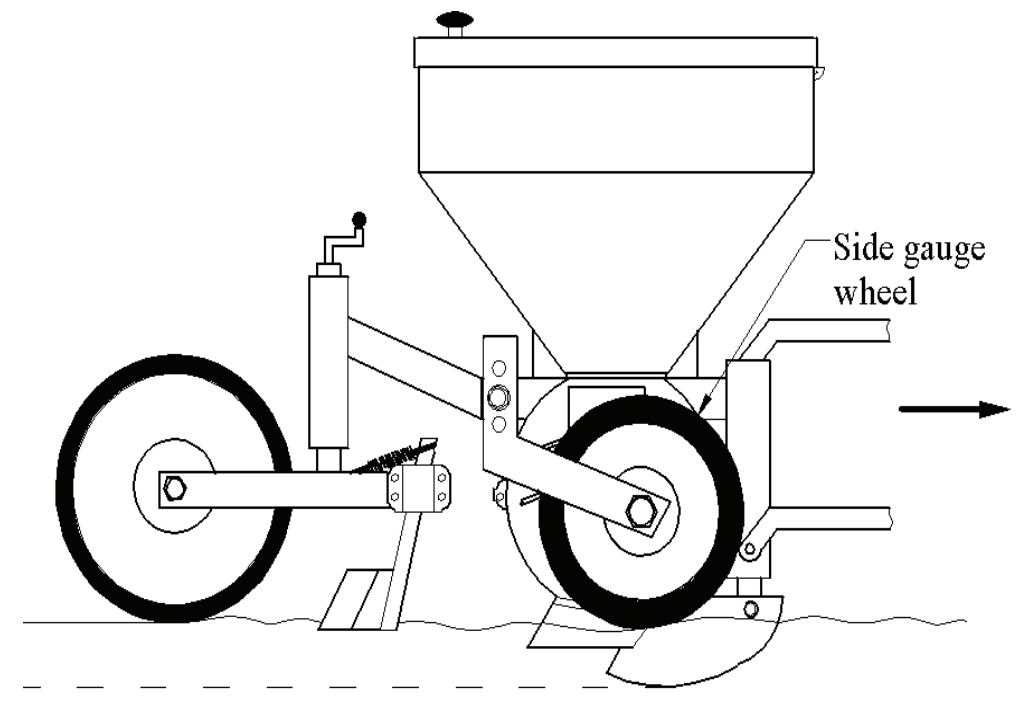

(b) 


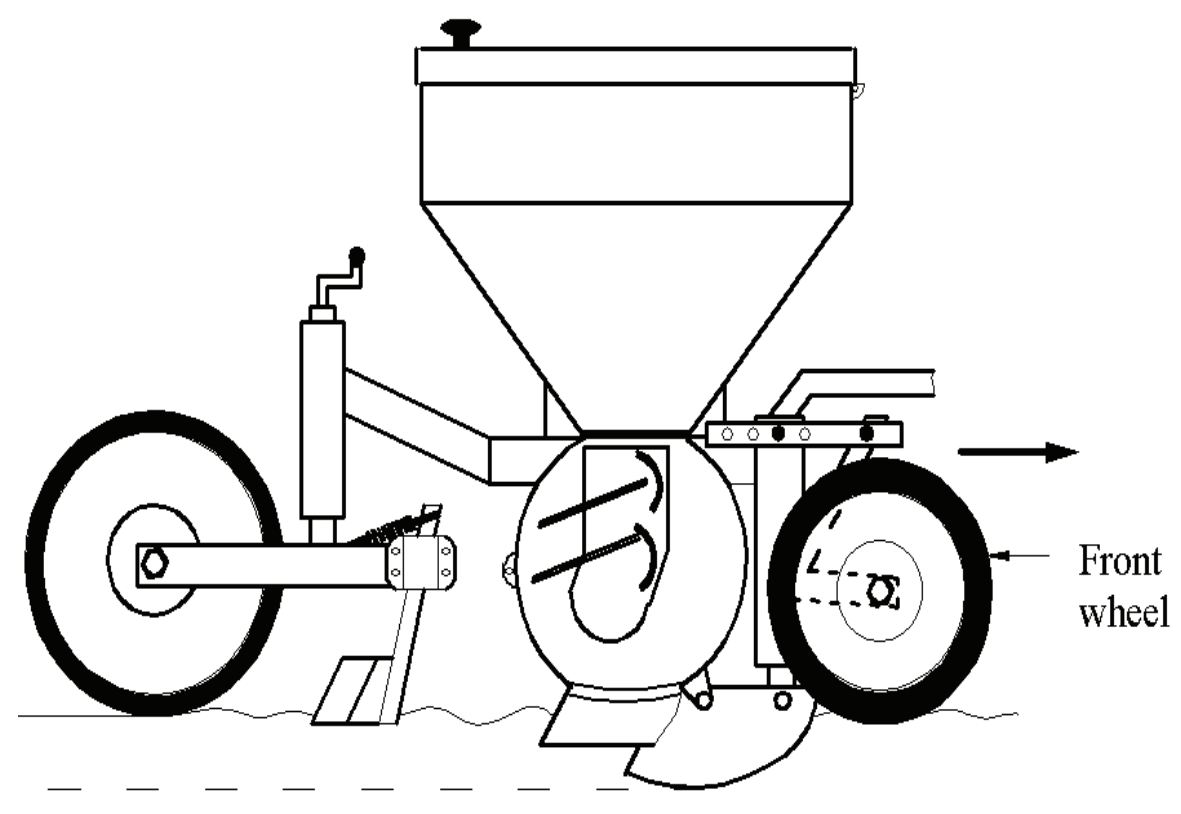

(c)

Fig. 1. Depth-control components of no-till seeders. (a) Rear presswheel, (b) Side gauge wheel, (c) Front wheel

The conventional seed meter devices for drills often result in poorly spaced stands with many gaps. To compensate for this stand variability, many operators will over-seed their stands by $10-20 \%$. The interest in the drills with singulation devices similar to row-crop meter devices is due to the possibility to improve stands, reduce seed cost, and reduce variability seen in conventional flute-meter devices.

With these inherent problems of conventional fluted-meter devices, manufacturers have designed a spiral cup, belted meters, and meter devices that singulate out the individual seeds (potential to plant corn). Designers also moved the meter device closer to the ground to reduce the travel distance to the seed placement. Manufacturers have also adapted rowcrop seeders for narrow row to give producers the seed singulation and spacing accuracy as well as a machine that could be used for both drilled and row-crops (Grisso et al., 2009).

Parish et al. (1999) designed a prototype belt-metering seeder for soybeans. The prototype was compared with commercially available seeders equipped with fluted wheel, brush, or finger metering systems. At forward speeds of 3.2 to $9 \mathrm{~km} \mathrm{~h}^{-1}$, the prototype set for a nominal spacing of $24 \mathrm{~mm}$ was able to meter soybeans with a mean spacing of 23 to $30 \mathrm{~mm}$ and a quality of feed index of 38 to $46 \%$. Sowing uniformity of the prototype was not better than the sowing uniformity of the three commercial seeders.

Some research was conducted on precision vacuum seeders to evaluate them for row crops such as maize (Zea mays L.) and soybean (Glycine max L.). Precision seeders place seeds at the required spacing and provide a better growing area per seed. There are two common types of precision seeders: belt and vacuum. Precision vacuum seeders have a metering plate with metering holes on a predetermined radius. A vacuum is applied to these metering holes by 
means of a race machined in a backing plate. As the plate rotates, the vacuum applied to the metering holes enables them to pick up seeds from the seed hopper. Precision vacuum seeders provide a higher dosage preciseness with lower rate of seed damage caused by seed plate, and broader spectrum of applicability. An additional advantage of these machines is that upkeep and drift of seeds can be controlled by eyes and adjusted which also provides a more successful sowing (Soos et al., 1989).

Giannini et al. (1967) published a thorough discussion of the need for precision sowing and discussed the development of a very successful precision seeder that used vacuum principles for singulation. Compared with the standard bulk metering seeder, this vacuum seeder used $90 \%$ less seed, thus reducing thinning time and resulting in improved yields. Hudspeth and Wanjura (1970) developed a vacuum meter system for sowing cotton (Gossypium hirsutum L.). Field tests showed that plant spacing and emergence were better when the vacuum meter system was used compared with a conventional grain drill with a double-run meter, which consists of a cast iron disc corrugated at both sides by fine and coarse pockets to suit different sizes of seeds. Parish and Bracy (1998) hypothesised that a vacuum seeder should meter a wider range of seed size more uniformly than a belt seeder, since the holes in the seed plate must only be smaller than the smallest seeds in the lot. Karayel and Ozmerzi (2004) assessed the use of a precision vacuum seeder for hill-drop sowing of melon (Cucumis melo) and watermelon (Citrullus lanatus). They reported that the precision vacuum seeder was effective at hill-drop sowing of melon and watermelon.

Little work has been done to evaluate using possibilities of conventional seeders for minimum and no-till systems. Raoufat and Mahmoodieh (2005) evaluated field performance of a conventional row crop seeder with two types of coulter attachment (plain/notched coulters) in two tillage systems (mouldboard/ chisel ploughs) for maize cropping after a wheat harvest. Chisel ploughing followed by a coulter-seeder appears to be a good alternative to a more conventional cropping system, offering advantages for conservation farming and better plant establishment. Raoufat and Matbooei (2007) developed proper cleaning wheels for conventional precision seeders and evaluated the field performance of the new row cleaner seeder at various levels of previous wheat residue and forward speed for no-till sowing of maize. Row cleaners performed best at the forward speed of $10 \mathrm{~km} \mathrm{~h}^{-1}$, retaining an average residue cover of $920 \mathrm{~kg} \mathrm{ha}^{-1}$ compared to $1350 \mathrm{~kg} \mathrm{ha}^{-1}$ for plots planted without using row cleaners.

The primary disadvantage of no-till farming is the need for specialized sowing equipment designed to plant seeds into undisturbed soil and crop residues. Because no-till is a relatively new technique, new and different equipment has to be purchased or hired. The price of the no-till seeders is the main limitation to no-till in Turkey. Modifying the conventional seeders commonly used in Turkey may be a key factor in the shift to no-till sowing. Objective of this research was to evaluate possibilities of using a conventional precision seeder equipped with hoe and double disc furrow openers for no-till sowing of soybean.

\section{Materials and methods}

The study was conducted in July 2006 at the Research and Application Land, Faculty of Agriculture, University of Akdeniz, Antalya, Turkey. The soil (Eutric Vertisols by FAO/UNESCO), composed of $41 \%$ sand, $26 \%$ silt, and $33 \%$ clay, was classified as clay-loam, and residue from the previous wheat crop was on the soil. The wheat was harvested by a combine harvester leaving relatively uniform stubble. The average residue mass before the 
sowing operation was $2.8 \mathrm{t} \mathrm{ha}^{-1}$. Moisture content of the soil for the top $50 \mathrm{~mm}$ before sowing was $22.1 \%$ dry basis. Soybean (Glycine max L.) seed with a mean mass per seed of $212 \mathrm{mg}$ were used for all treatments. Two different types of furrow openers (hoe and double disc) and three forward speeds (1.0, 1.5 and $\left.2.0 \mathrm{~m} \mathrm{~s}^{-1}\right)$ were used as treatments. Plot dimensions were $5 \mathrm{~m} \times 25 \mathrm{~m}$ and the measurements taken in each plot were: the distance between seedlings, depth of seed placement and number of seeds emerged per day.

A precision vacuum seeder was modified to allow simultaneous mounting of two different furrow openers, with one furrow opener on one row unit and the second furrow opener on another row unit, on the two-row seeder. The seeder was a general-purpose Sonmezler PMD seeder designed for row crops such as maize and soybean (Fig. 2) (Sonmezler Company, Adana, Turkey). A seed plate operated in a vertical plane and required a vacuum of $3.5-8.0 \mathrm{kPa}$ to select a seed. Air suction from the holes of the seed plate caused the seed to stick to holes $4 \mathrm{~mm}$ in diameter. Seed was released from the rotating plate by blocking air suction over the opener, which had no seed tube.

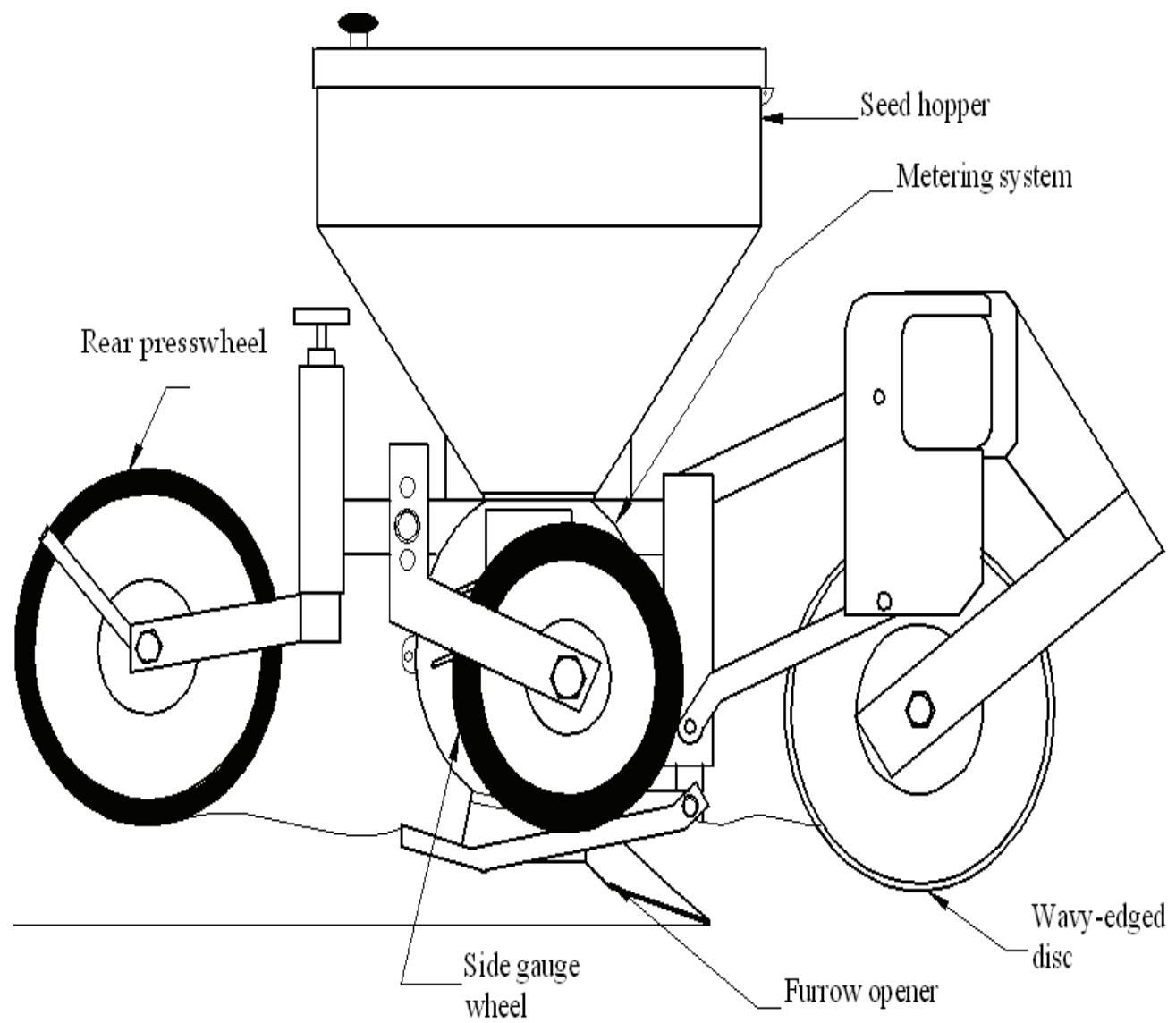

Fig. 2. The modified precision vacuum seeder for no-till sowing (Direction of travel is left to right) 
Each sowing unit was independently mounted on a four-bar parallel linkage equipped with joint springs to apply downward force on the sowing unit and was composed of a furrow opener followed by a presswheel, which closed and compacted the seed furrow. The seed metering system was adjusted for a nominal seed spacing of $102 \mathrm{~mm}$ in the row. Furrow openers was adjusted for a nominal sowing depth of $50 \mathrm{~mm}$. The seeder was calibrated in the laboratory before field operation.

The furrow opener of the precision vacuum seeder was a runner-type opener (widely used when cropping maize and soybean in ground that has been conventionally tilled) before modifying the seeder for no-till sowing. Hoe and double disc-type furrow openers were used in the study because disc and hoe openers are becoming more popular where minimum and no-till systems are used and there is a greater amount of residue left on the surface. The hoe-type furrow opener was made from grey cast iron, with its cutting edge quenched to increase hardness and wear resistance. A pair of mild steel wings were welded to either side of the opener to complete the assembly. The double disc-type furrow openers were designed and fabricated from high-carbon steel plates $3.5 \mathrm{~mm}$ thick (Fig. 3).

Each furrow opener assembly comprised a vertical shank and an axle to which the furrow opener was mounted via a bearing. The opener shank assembly was designed in such a way that the opener could easily float, avoid side force and follow the direction of machine travel. A 400-mm diameter wavy-edged disc was mounted in front of furrow opener. The longitudinal distance from the center of each wavy-edged disc to the leading edge of the furrow opener was set at $450 \mathrm{~mm}$.

The side gauge wheels, which maintained a constant sowing depth, were $60 \mathrm{~mm} \times 260 \mathrm{~mm}$ soft crowned gauge wheels mounted vertically, at the same longitudinal position as the center of the furrow openers and positioned so the lateral distance from the inner side of the gauge wheel was $30 \mathrm{~mm}$ outboard of the furrow opener. There were no side gauge wheels or wavy-edged disc on the seeder before it was modified for no-till sowing. Down force of all depth-control wheels was set at $750 \mathrm{~N}$ based on the soil condition in this study.

After sowing, the distribution of the seeds along the length the row, sowing depth uniformities, mean emergence times (MET), and percent emergence (PE) were compared. The distances between adjacent plants in each furrow were measured. Spacings between adjacent plants were measured in the field 17 days after sowing for about 50 soybean plants for each treatment. The depths of the seeds beneath the soil surface were measured. A mark was made on the plant at the ground level. The plant was then dug out and the entire stem length below the mark was taken as the effective sowing depth. Mean sowing depth and coefficient of variation of depth were calculated from these measurements.

The sowing uniformity of the distribution pattern along the length of the row was analyzed using the methods described in Kachman and Smith (1995). The multiple index is the percentage of plant spacings that were less than or equal to half of the nominal spacing and indicates the percentage of multiple seed drops. Miss index is the percentage of plant spacings greater than 1.5 times the nominal seed spacing and indicates the percentage of missed seed locations or skips.

Quality of feed index (QFI) is the percentage of plant spacings that were more than half but no more than 1.5 times the nominal spacing. QFI is 100\% minus miss and multiple indexes and is a measure of the percentages of single seed drops. Larger values of QFI indicate better performance than smaller values. Precision (PREC) is the coefficient of variation of the 

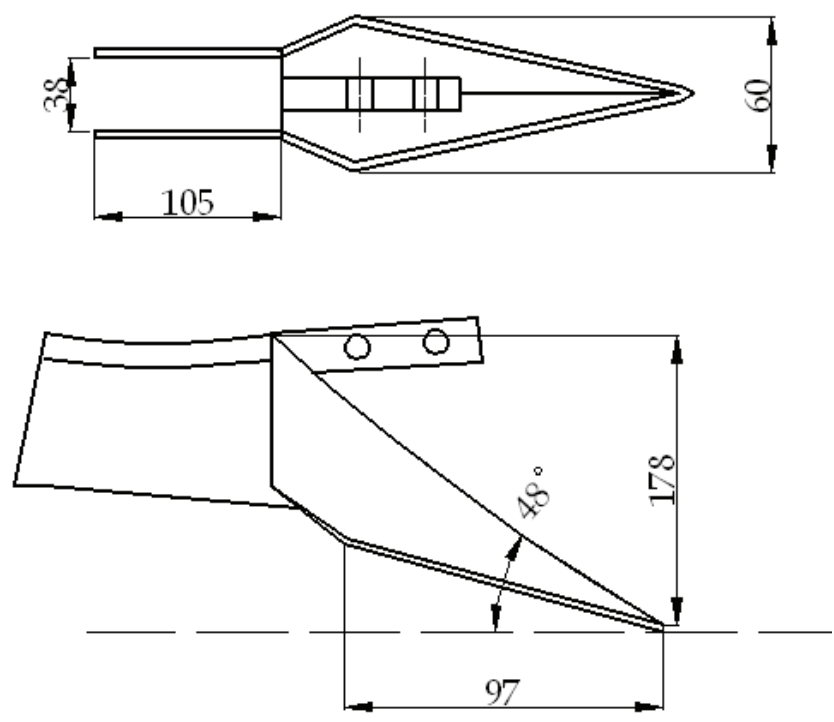

(a)
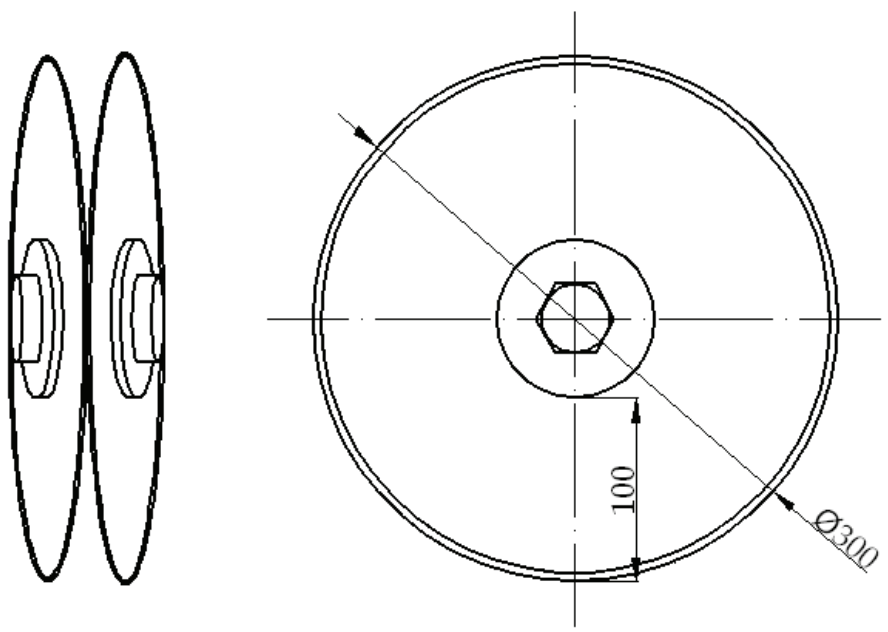

(b)

Fig. 3. Furrow openers as used in the experiment. Units of dimensions are mm. (a) Hoe-type opener (Upper view is top view and lower view is right side view), (b) Double disc-type opener (Left view is front view and right view is side view) 
spacings (length) between the nearest plants in a row that are classified as singles after omitting the outliers consisting of misses and multiples. According to Kachman and Smith (1995), the theoretical upper limit for precision is 50\% and this distribution of spacings would indicate that the theoretical spacing was incorrectly specified and, therefore, this level of precision is unfavourable. A practical upper limit on the value of precision is $29 \%$. While there is a theoretical upper limit of $50 \%$ on the precision, values consistently greater than $29 \%$ should be viewed with suspicion.

Seedling counts were made in $25 \mathrm{~m}$ of row per treatment every day during the emergence period. From these counts, mean emergence time and percent emergence were calculated as (Bilbro \& Wanjura, 1982; Karayel \& Ozmerzi, 2002):

$$
\begin{gathered}
M E T=\frac{N_{1} T_{1}+N_{2} T_{2}+\ldots \ldots . .+N_{n} T_{n}}{N_{1}+N_{2}+\ldots \ldots . .+N_{n}} \\
P E=\frac{S_{t e}}{n}
\end{gathered}
$$

where $\mathrm{N}_{1, \ldots ., \mathrm{n}}$ is the number of seedlings emerging since the time of previous count; $\mathrm{T}_{1, \ldots, \mathrm{n}}$ is the number of days after sowing; $S_{\text {te }}$ is the number of total emerged seedlings per meter; $n$ is the number of seeds sown per meter; MET is the mean emergence time, in days and PE is the percent emergence.

A completely randomised design was selected for the experiment. Each treatment was replicated three times. Analysis of variance was determined using the SAS package (Cary, N.C.) to examine the effects of treatments. Duncan's multiple-range tests were used to identify significantly different means within dependent variables at $\mathrm{P} \leq 0.05$.

\section{Results and discussion}

Performance of a modified precision vacuum seeder for no-till sowing of soybean was analyzed related to the sowing uniformity of the distribution pattern along the length of the row, uniformity of sowing depth, mean emergence time and percent emergence. Multiple index, miss index, quality of feed index, sowing depth, mean emergence time and percent emergence were combined for analysis of variance to determine significant differences in the variability among the parameters.

The results of the analysis show that the multiple index, miss index, and QFI of the distribution of the seeds along the length of the row were significantly influenced by the forward speed of the seeder (Fig. 4). Furrow openers did not have a significant effect on multiple index, miss index, and QFI. Increasing the forward speed of the seeder affected the performance of the furrow openers and the placement of the seeds, and caused multiple index to decreased and miss index to increase.

Larger values of quality of feed index indicate better performance than smaller values. In other words, the quality of feed index is a measure of how often the spacings are close to the nominal spacing (Kachman \& Smith, 1995). Mean comparisons of the quality of feed index values, as affected by forward speed, revealed that the highest quality of feed index values were obtained at the forward speed of $1.5 \mathrm{~m} \mathrm{~s}^{-1}$. The seed spacings obtained from the 


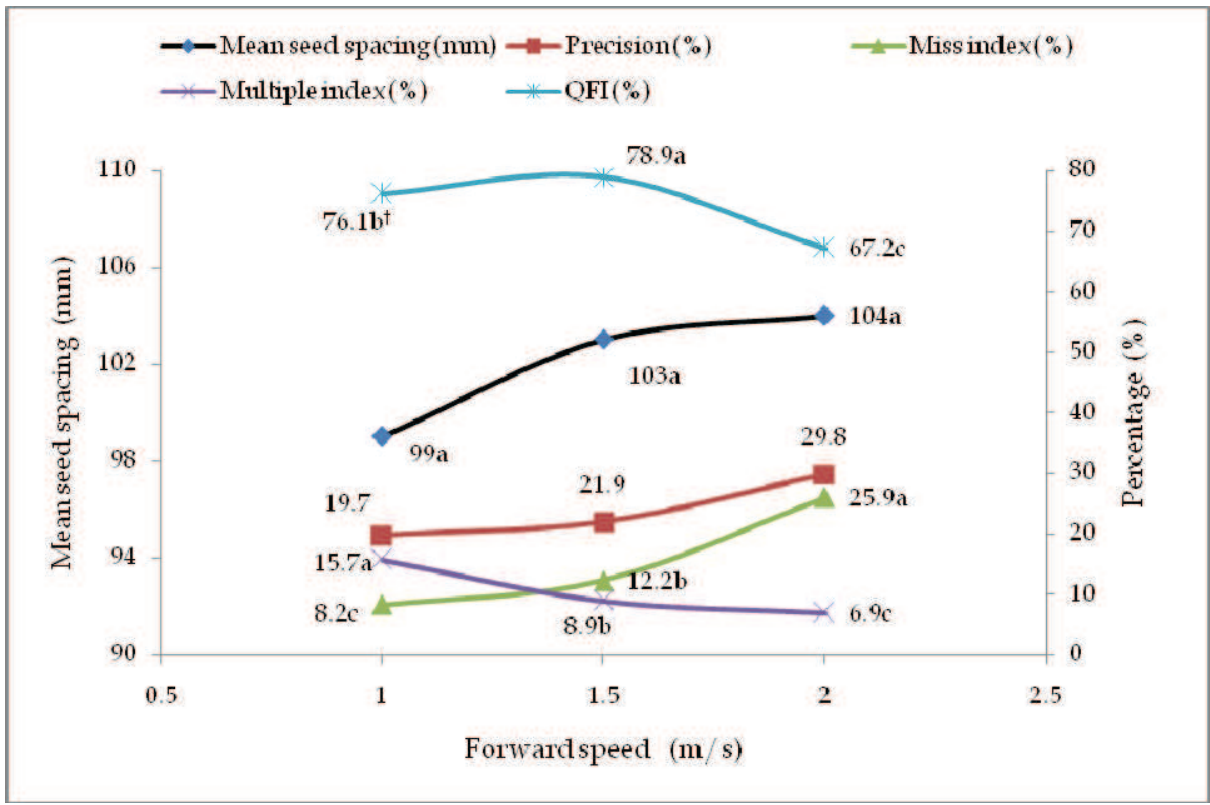

(a)

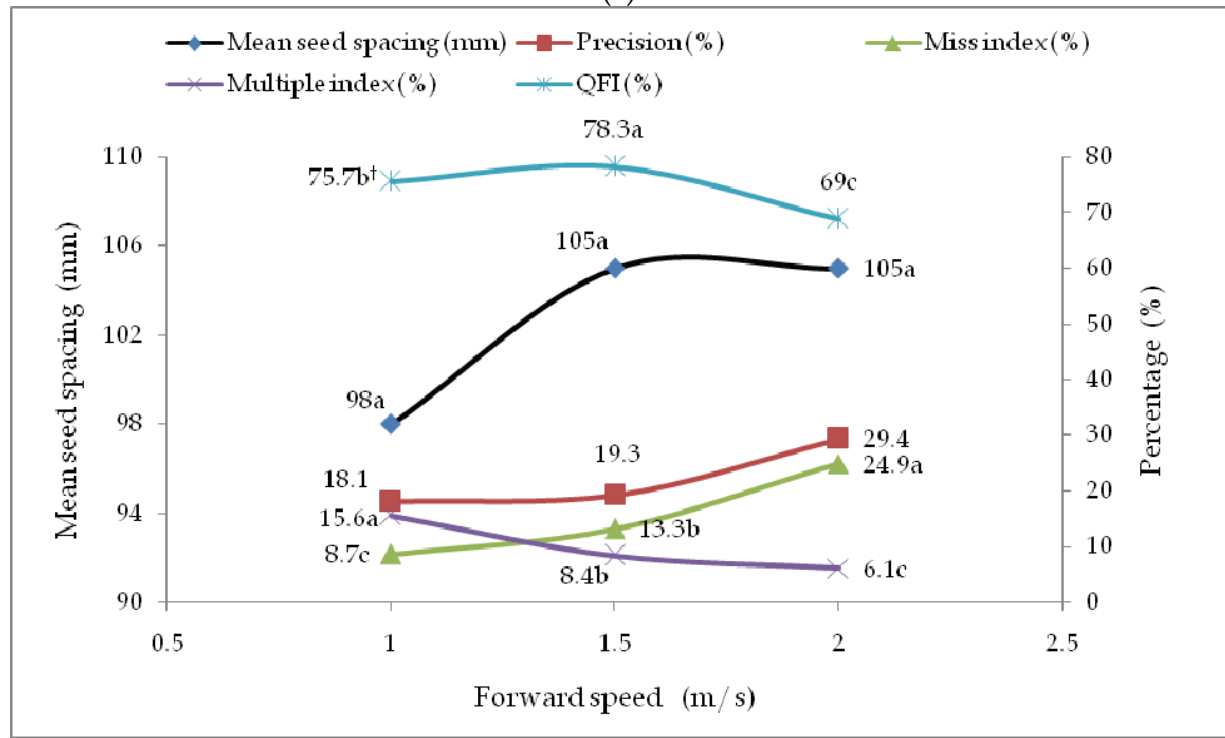

(b)

t: Means followed by same letter on a line are not significantly different at probability $\mathrm{P}=0.05$, by Duncan's multiple range test.

Fig. 4. Uniformity of the sowing distribution pattern along the length of the row for soybean at different forward speeds and for different furrow openers. a) Hoe-type opener, (b) Double disc-type opener 
forward speed of $1.5 \mathrm{~m} \mathrm{~s}^{-1}$ were closer to the theoretical spacing. Precision is a measure of the variability in spacings between plants after accounting for variability due to both multiples and skips. A practical upper limit for precision is $29 \%$. Smaller values of precision indicate better performance than larger values (Kachman \& Smith, 1995).

Comparison of data on overall average precision as affected by forward speed and furrow opener treatments shows a significantly higher precision for the forward speed of $2.0 \mathrm{~m} \mathrm{~s}^{-1}$ as compared to the forward speeds of 1.0 and $1.5 \mathrm{~m} \mathrm{~s}^{-1}$. The negative effect of the forward speed of $2.0 \mathrm{~m} \mathrm{~s}^{-1}$ on the precision is evident.

In general it can be concluded that as the forward speed decreases, precision declines and seeder performance improves. The results support reports from Barut (1996), Karayel et al. (2004) and Karayel and Ozmerzi (2001) who found that the pattern efficiency of the vacuum seeder differed most at lesser or greater vacuum pressures and faster forward speeds. In this research, precisions of the seeder were poorer at greater forward speeds.

Using the double disc-type opener resulted in lower values of the precision than the hoetype opener. The precision results for both types of seed show that the best uniform plant spacing occurred for the double disc-type furrow opener at the forward speed of $1.0 \mathrm{~m} \mathrm{~s}^{-1}$ and the least uniform occurred for the hoe-type furrow opener at the forward speed of $2.0 \mathrm{~m} \mathrm{~s}^{-1}$. The range of precision of forward speeds of 1.0 and $1.5 \mathrm{~m} \mathrm{~s}^{-1}$ experienced in this study was $18.1-21.9 \%$ for soybean sowing, and these are acceptable, as they are well below $29 \%$.

Analysis of the soybean sowing data, combined, showed significant differences in mean sowing depth occurring among forward speeds and furrow openers. Fig. 5 shows the influence of the forward speeds and furrow openers on uniformity of sowing depth. Increasing the forward speed affected the performance of the furrow openers and the placement of the seeds, and caused the mean sowing depth to decrease and the coefficient of variation of depth to increase. The actual mean sowing depths are nearly equal to nominal sowing depth for the forward speed of $1.0 \mathrm{~m} \mathrm{~s}^{-1}$.

The mean sowing depth and coefficient of variation of depth for the hoe-type opener are generally greater than for the double disc-type opener for all forward speeds. While the best uniform sowing depth occurred for the double disc-type opener at the forward speed of $1.0 \mathrm{~m} \mathrm{~s}^{-1}$, the worst results occurred for the hoe-type opener at the forward speed of $2.0 \mathrm{~m} \mathrm{~s}^{-1}$. Fig. 6 shows that the forward speed of $2.0 \mathrm{~m} \mathrm{~s}^{-1}$ resulted in the least mean emergence time, and the reason might be shallower sowing depth at this relatively high forward speed. It should be noted that the results refer to mean emergence times of soybean seeds, for no-till sowing, ranging from 6.4 to 7.7 days for soybean.

Analysis of the soybean sowing data, combined, showed a significant difference in percent emergence due to forward speed and furrow opener $(P<0.05)$. Fig. 7 shows the significantly greater average percent emergence for the double disc-type opener as compared to the hoetype opener. Increasing the forward speed affected the performance of the furrow openers and the placement of the seeds, and caused the final percent emergence to decrease.

The forward speed of $1.0 \mathrm{~m} \mathrm{~s}^{-1}$ had the greatest percent emergence, due to the most uniform sowing depth. Our results support reports from Heege (1993), Ozmerzi et al. (2002), Karayel (2005), Karayel and Ozmerzi (2007a \& b), and Canakci et al. (2009) who found that percent emergence was negatively affected by large variability in sowing depth. 


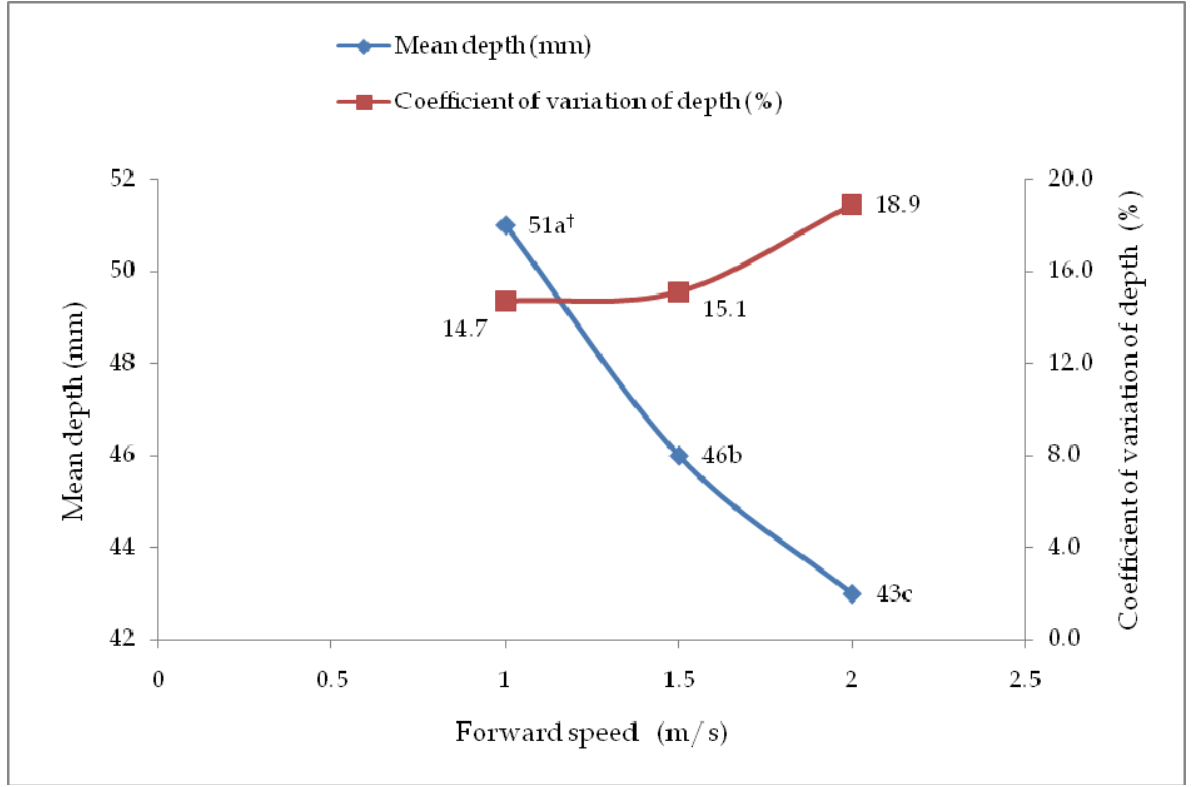

(a)

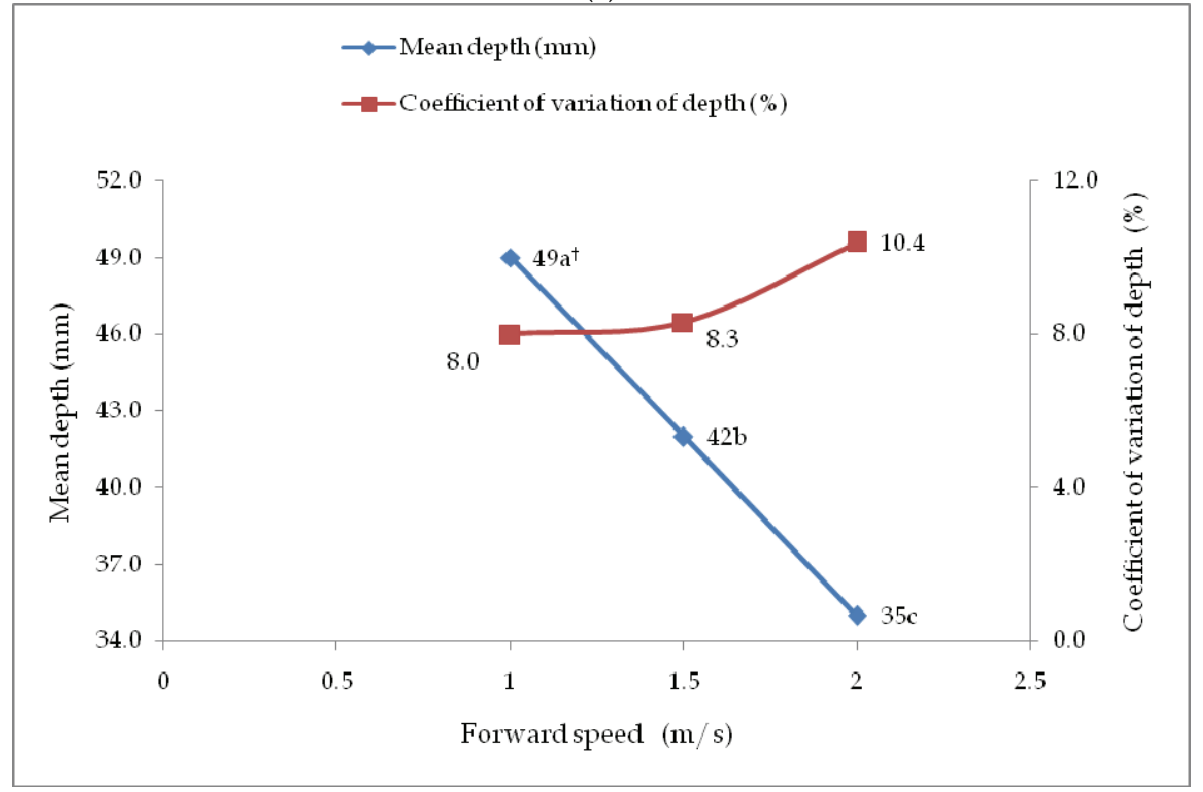

(b)

†: Means followed by same letter on a line are not significantly different at probability $\mathrm{P}=0.05$, by Duncan's multiple range test.

Fig. 5. Uniformity of sowing depth for different forward speeds and furrow openers. (a) Hoe-type opener, (b) Double disc-type opener 


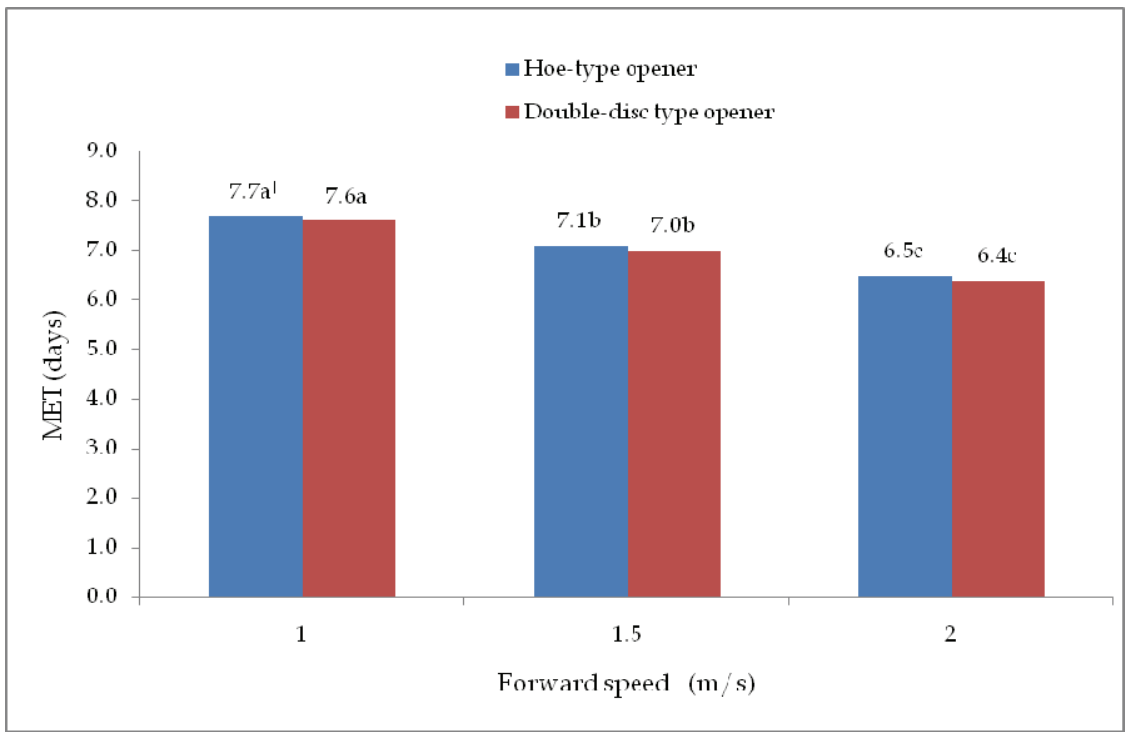

t: Means followed by same letter on columns are not significantly different at probability $\mathrm{P}=0.05$, by Duncan's multiple range test.

Fig. 6. Mean emergence time (MET) of soybean seeds for different forward speeds and furrow openers

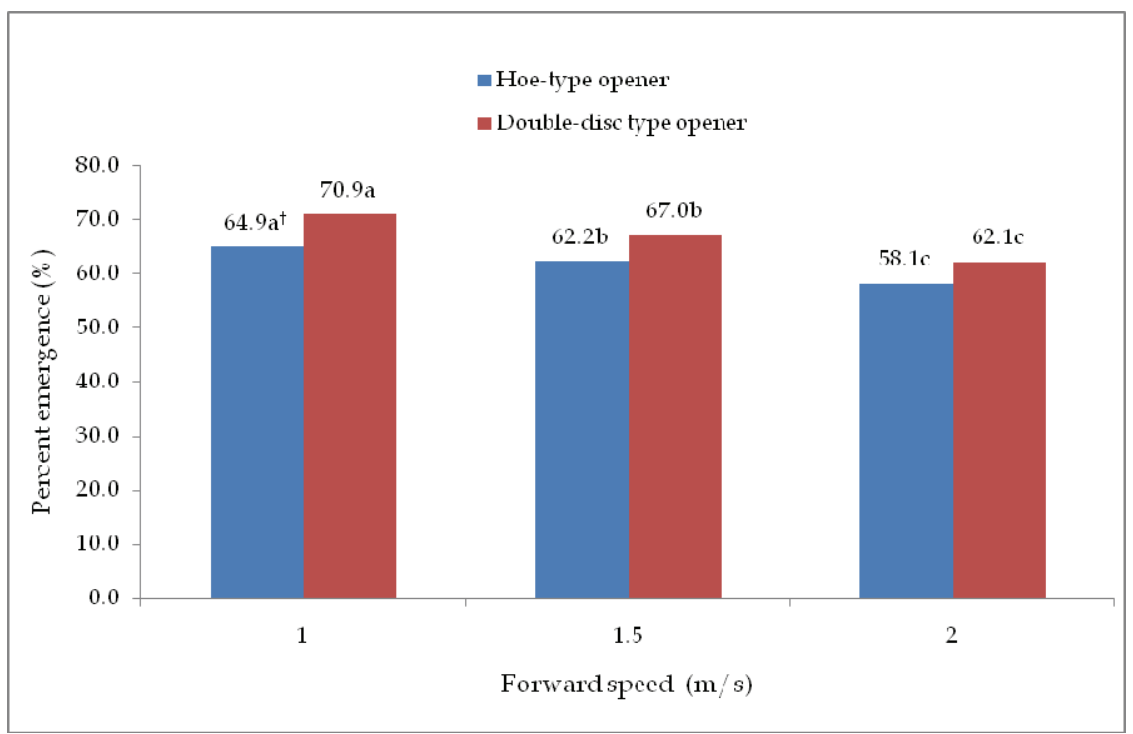

t: Means followed by same letter on columns are not significantly different at probability $\mathrm{P}=0.05$, by Duncan's multiple range test.

Fig. 7. Percent emergence (PE) of soybean seeds for different forward speeds and furrow openers 


\section{Conclusions}

The possible impact of this research is that farmers can benefit from advantages of a no-till system by modifying their existing seeders for no-till sowing of soybean. Modifying the conventional precision seeders commonly used in developing countries may be a key factor in the shift to no-till sowing.

On the basis of this research we reached the following conclusions. Increasing the forward speed of a modified precision vacuum seeder increased the precision for the distribution of seeds along the length of the row and increased the coefficient of variation of depth, due to the effect of speed on the performance of the furrow openers and placement of the seeds. The greatest emergence time and percent emergence occurred when the forward speed was $1.0 \mathrm{~m} \mathrm{~s}^{-1}$.

It can be concluded that the position of the seed in the soil effects mean emergence time and percent emergence of soybean. Double disc-type openers performed better than the hoetype opener, according to the percent emergence and the uniformity of the distribution pattern along the length of the row and sowing depth. As a result of this experiment, improved precision of no-till sowing of soybean can be attained by using a forward speed of 1.0 or $1.5 \mathrm{~m} \mathrm{~s}^{-1}$ with a modified precision vacuum seeder equipped with a double disc-type furrow opener.

\section{Acknowledgement}

The chapter was partly supported by the Scientific Research Administration Unit of Akdeniz University, Antalya, Turkey.

Some parts of this chapter was derived from an original paper published in Soil and Tillage Research [104 (2009) 121-125], entitled "Performance of a modified precision vacuum seeder for no-till sowing of maize and soybean" by D. Karayel.

\section{References}

Baker, C.J.; Saxton, K.E. \& Ritchie, W.R. (2002). No-tillage Seeding: Science and Practice, 2nd edition. CAB International, Oxford, UK.

Barut, Z.B. (1996). Determination of the Optimum Working Parameters of a Precision Vacuum Seeder. PhD Thesis. Cukurova University, Institute of Natural and Applied Sciences, Adana, Turkey.

Bilbro, J.D. \& Wanjura D.F. (1982). Soil crust and cotton emergence relationship. Transactions of the ASAE, 25(4), 1484-1487.

Canakci, M.; Karayel, D.; Topakci, M. \& Koc, A. (2009). Performance of a no-till seeder under dry and wet soil conditions. Applied Engineering in Agriculture, 25(4), 459-465.

Chen, Y.; Tessier, S. \& Irvine, B. (2004). Drill and crop performances as affected by different drill configurations for no-till seeding. Soil Tillage Research, 77(2): 147-155

Ess, D.R.; Hawkins, S.E; Young, J.C. \& Christmas, E.P. (2004). Evaluation of the performance of a belt metering system for soybeans planted with a Grain Drill. ASAE/CSAE Meeting Paper No: 041085. St. Joseph, Mich.: ASABE

Giannini, G.R.; Chancellor, W.J. \& Garrett, R.E. (1967). Precision planter using vacuum for seed pickup. Transactions of the ASAE, 10 (2), 607-610 614. 
Grisso, R.; Holshouser D. \& Pitman, R. (2009). Equipment Considerations for No-till Soybean Seeding. Virginia Cooperative Extension, Virginia Polytechnic Institute and State University, Virginia State, Petersburg.

Heege, H.J. (1993). Seeding methods performance for cereals, rape and beans. Transactions of the ASAE, 36 (3), 653-661.

Hudspeth, E.B. \& Wanjura, D.F. (1970). A planter for precision depth and placement of cotton seed. Transactions of the ASAE, 13 (2), 153-155.

Kachman, S.D. \& Smith, J.A. (1995). Alternative measures of accuracy in plant spacing for planters using single seed metering. Transactions of the ASAE, 38 (2), 379-387.

Karayel, D. \& Ozmerzi, A. (2001). Effect of forward speed and seed spacing on seeding uniformity of a precision vacuum metering unit for melon and cucumber seeds. Journal of Faculty of Agriculture Akdeniz University, Antalya, 14 (2), 63-67.

Karayel, D. \& Ozmerzi, A. (2002). Effect of tillage methods on sowing uniformity of maize. Cananadian Biosystems Engineering, 44, 23-26.

Karayel, D.; Barut, Z.B. \& Ozmerzi, A. (2004). Mathematical modelling of vacuum pressure on a precision seeder. Biosystems Engineering, 87 (4), 437-444.

Karayel, D. \& Ozmerzi, A. (2004). Effect of forward speed on hill dropping uniformity of a precision vacuum seeder. Horticultural Technology, 14 (3), 364-367.

Karayel, D. (2005). Effects of Coulters and Depth Control Units of a Seeder on Sowing Quality for Precision Sowing. PhD Thesis. Akdeniz University, Institute of Natural and Applied Sciences, Antalya, Turkey.

Karayel, D. \& Ozmerzi, A. (2007a). Comparison of vertical and lateral seed distribution of furrow openers using a new criterion. Soil and Tillage Research, 95, 69-75.

Karayel, D. \& Ozmerzi, A. (2007b). Effect of furrow openers and depth control units of a seeder on field seedling emergence. Journal of Faculty of Agriculture Akdeniz University, Antalya, 20 (2), 153-161

Karayel, D. \& Ozmerzi, A. (2008). Evaluation of three depth control components on seed placement accuracy and emergence for a precision planter. Applied Engineering in Agriculture, 24(3), 271-276.

Morrison, J. E. \& Gerik T.J. (1985a). Planter depth control: I. Predictions and projected effects on crop emergence. Transactions of the ASAE, 28(5): 1415-1418.

Morrison, J. E. \& Gerik T.J. (1985b). Planter depth control: II. Empirical testing and plant responses. Transactions of the ASAE, 28(6): 1744-1748.

Ozmerzi, A.; Karayel, D. \& Topakci, M. (2002). Effect of sowing depth on precision seeder uniformity. Biosystems Engineering, 82 (2), 227-230.

Parish, R.L. \& Bracy, R.P. (1998). Metering nonuniform vegetable seed. Horticultural Technology, 8 (1), 69-71.

Parish, R.L.; McCoy, J.E \& Bracy, R.P. (1999). Belt-type seeder for soybeans. Applied Engineering in Agriculture, 15(2) 103-106.

Raoufat, M.H. \& Mahmoodieh, R.A. (2005). Stand establishment responses of maize to seedbed residue, seed drill coulters and primary tillage systems. Biosystems Engineering, 90 (3), 261-269.

Raoufat, M.H. \& Matbooei, A. (2007). Row cleaners enhance reduced tillage planting of corn in Iran. Soil and Tillage Research, 93, 152-161.

Soos, P.; Szule, Z.S. \& Fuzy, J. (1989). A Comparative Evaluation of Modern Sugar Beet Drills, Bulletin of the University of Agricultural Science, Gödöllo, Hungary, vol. 1, 66170. 


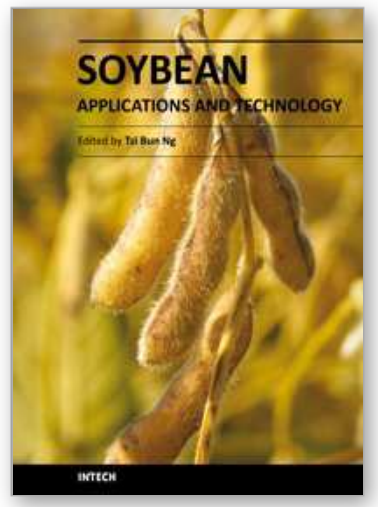

\section{Soybean - Applications and Technology \\ Edited by Prof. Tzi-Bun Ng}

ISBN 978-953-307-207-4

Hard cover, 402 pages

Publisher InTech

Published online 26, April, 2011

Published in print edition April, 2011

Soybean is an agricultural crop of tremendous economic importance. Soybean and food items derived from it form dietary components of numerous people, especially those living in the Orient. The health benefits of soybean have attracted the attention of nutritionists as well as common people.

\section{How to reference}

In order to correctly reference this scholarly work, feel free to copy and paste the following:

Davut Karayel (2011). Direct Seeding of Soybean Using a Modified Conventional Seeder, Soybean Applications and Technology, Prof. Tzi-Bun Ng (Ed.), ISBN: 978-953-307-207-4, InTech, Available from: http://www.intechopen.com/books/soybean-applications-and-technology/direct-seeding-of-soybean-using-amodified-conventional-seeder

\section{INTECH}

open science | open minds

\section{InTech Europe}

University Campus STeP Ri

Slavka Krautzeka 83/A

51000 Rijeka, Croatia

Phone: +385 (51) 770447

Fax: +385 (51) 686166

www.intechopen.com

\section{InTech China}

Unit 405, Office Block, Hotel Equatorial Shanghai

No.65, Yan An Road (West), Shanghai, 200040, China

中国上海市延安西路65号上海国际贵都大饭店办公楼405单元

Phone: +86-21-62489820

Fax: $+86-21-62489821$ 
(C) 2011 The Author(s). Licensee IntechOpen. This chapter is distributed under the terms of the Creative Commons Attribution-NonCommercialShareAlike-3.0 License, which permits use, distribution and reproduction for non-commercial purposes, provided the original is properly cited and derivative works building on this content are distributed under the same license. 